\title{
INTRA-INDUSTRY TRADE IN THE MANUFACTURING SECTOR OF SOUTH AFRICA
}

\author{
T G Gebreselasie* and A C Jordaan
}

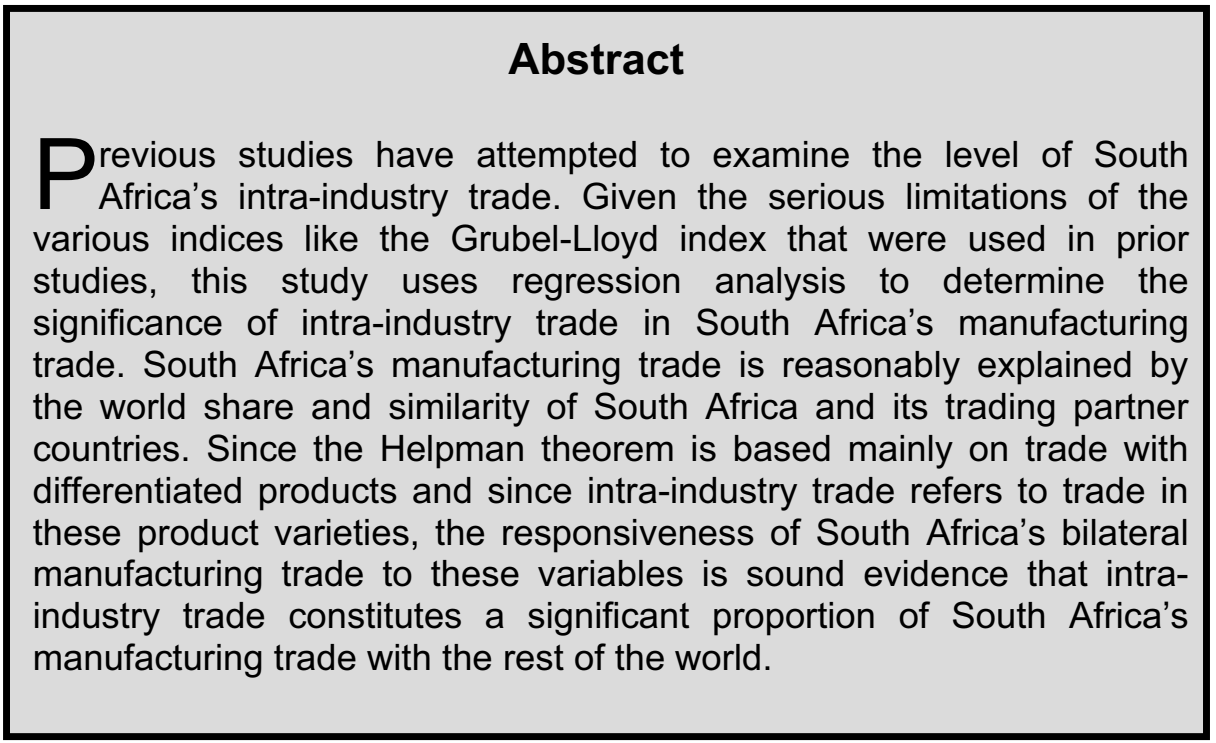

\section{Introduction}

Trade among developed countries comprises a significant portion of intra-industry trade. Since intra-industry trade is beyond the explanatory scope of the classical trade theories, economists have been in search of theories that explain the increasing prominence of intra-industry trade, particularly among developed economies. The Heckscher-Ohlin theorem with a continuum of goods and imperfect competition models have been found to best describe intra-industry trade among developed economies.

This paper focuses on and empirically tests a theorem that builds on the latter, and is commonly referred to as the Helpman theorem (1987). According to this theorem, the volume of trade among a group of countries increases as the size of the group (relative to the world) increases and as the countries constituting the group become more similar. The theorem gains strong empirical support among a group of OECD countries (Debaere, 2004; Hummels and Levinsohn, 1995). However, there is little empirical support to this theorem from a group of non-

\footnotetext{
* Respectively Human Sciences Research Council, Employment, Growth and Development Initiative, Private Bag X41, Pretoria 0001 and Department of Economics, University of Pretoria, Republic of South Africa. The authors would like to thank the anonymous referee for his valuable comments on the earlier version.

Email: tgebreselasie@hsrc.ac.za (or tgselasie@yahoo.com) and andre.jordaan@up.ac.za
} 
OECD countries. It is argued that there are sufficient reasons for the theorem to fall short of explaining bilateral trade among developing countries (Debaere, 2004). The main reason being that most developing countries specialize in lower-end products that do not bear any potential for product differentiation. Differentiation of a product is the principal foundation for the Helpman theorem.

The belief that the Helpman theorem (1987) and gravity equations explain trade that occur solely between developed countries originates from the aspect of product differentiation. The perception is that these developed countries mostly trade in higher-end products which allow rooms for differentiation. Hence, as a country from the developing world, South Africa's bilateral manufacturing trade is not expected to respond convincingly to the main variables of the Helpman theorem. It is further argued that South Africa's exports are mainly resource-based. Nevertheless, there were studies in the past (e.g. Isemonger, 2000; Parr, 2000) that attempted to measure the level of intra-industry trade of South Africa. According to the study of Isemonger (2000) that employs the Grubel-Lloyd index, it is found that there are some sectors of the South African economy that have a considerable proportion of intra-industry trade. The increasing significance of intra-industry trade in the South African manufacturing sector has also been identified in the study carried out by Parr (2000) using the Brülhart's B measure.

Building on and extending prior studies, this paper econometrically tests the Helpman theorem using South Africa's bilateral manufacturing trade. The theorem provides for a framework to determine the explanatory power of world share and similarity of trading partners, i.e., South Africa and each of its trading partners. If the model results in a statistically significant outcome and proves that the Helpman theorem holds in South Africa's bilateral manufacturing trade, one can argue that intra-industry trade dominates the bilateral manufacturing trade between South Africa and those countries that have similar economic size as South Africa.

The paper is organized as follows. The following section provides a brief review of empirical studies. The section on model specification offers a detailed description of the various specifications that will be estimated in this study. The data and all the sources used in this paper are given in Section 4. Section 5 presents and discusses the outputs from a regression analysis and the following section examines actual export figures to see whether they concur with the regression analysis. The last section concludes and highlights important policy implications.

\section{Empirical review}

The version of the gravity model that is built on the Helpman (1987) theorem is estimated in order to test whether trade among countries of similar size is bigger than trade among countries of unequal size.

Two sets of panel estimations for the OECD and non-OECD countries were conducted by Hummels and Levinsohn (1995) and Debaere (2004). Hummels and Levinsohn (1995) found significant and economically consistent signs for both variables that appear in Helpman's theorem: world share of trading countries' 
GDPs and their similarity in terms of size. Debaere, however, questions the findings and identifies econometric problems in the study of Hummels and Levinsohn (1995). According to Debaere, similarity of trading partners is found to explain bilateral trade for the group of OECD countries. He reports that, contrary to the study of Hummels and Levinsohn (1995), similarity is reported to be insignificant in explaining bilateral trade among non-OECD countries. The explanations for his findings lie in the nature of products that OECD and nonOECD countries develop and their varying level of economic development. Since products of the OECD countries appear similar, they allow each producing country the possibility of differentiation and export the differentiated products to the markets of other OECD member countries. As we know product differentiation is the basis for monopolistic competition and hence the new trade theory. In contrast, the room for differentiation is argued to be smaller in the case of non-OECD countries since they are less developed and their trade is mainly limited to lowerend products.

Isemonger (2000) examined the level of South Africa's intra-industry trade using two variations of the Grubel-Lloyd indices. He calculated the indices over the period 1993 to 1996 for the various categories identified by the Harmonized System (HS). According to his study, South Africa has predictably low levels of intra-industry trade among the primary product categories as well as low overall levels of intra-industry trade. It is only in certain manufacturing categories (e.g. clothing and textiles) that the level of intra-industry trade is generally higher. However, he found a very definite upward trend in the overall level of intraindustry trade. Parr (2000) conducted similar study during the same period but with a different index of intra-industry trade. Using Brülhart's B measure, Parr (2000) established that about $35 \%$ of the four digit HS industrial classifications for the manufacturing sector (out of a total of 743) exhibited sizable intra-industry trade between 1993 and 1998.

\section{Model specification}

A conventional gravity model has long been used to estimate bilateral trade among countries. Gravity equations are reduced form general equilibrium models. It includes importing and exporting countries' GDP, population sizes, price levels and other dummies to explain bilateral trade relationships. Distance is also included to take account of transportation costs.

The Helpman theorem is one of the simplest representations of a gravity model. The majority of earlier studies that used gravity models are cross-sectional studies without giving due regard to the heterogeneity of the countries being studied. South Africa has a long standing trading relationship with almost all countries of the world irrespective of their size. Not considering this heterogeneity aspect in this study introduces serious bias. In order to counter the adverse effect of countries' heterogeneity, this study employs panel econometric techniques. Out of the various specifications the fixed effect model (FEM) is chosen in this study since it is 
subject to a relatively limited number of preconditions in comparison to the random effects model (REM) ${ }^{1}$.

In this paper, the specific gravity equations to be estimated using fixed effects panel econometrics techniques are based on the following Helpman theorem (Feenstra, 2004: 146$)^{2}$ :

$$
\frac{\mathrm{VT}_{\mathrm{A}}}{\mathrm{Y}_{\mathrm{A}}}=\mathrm{S}_{\mathrm{A}}\left[1-\sum_{\mathrm{i} \in \mathrm{A}}\left(\frac{\mathrm{Y}_{\mathrm{i}}}{\mathrm{Y}_{\mathrm{A}}}\right)^{2}\right]
$$

Where $\mathrm{VT}_{\mathrm{A}}$ represents bilateral trade between countries in group $\mathrm{A} ; \mathrm{Y}_{\mathrm{A}}$ denotes the sum of GDPs of all countries in group $\mathrm{A}$; and $\mathrm{S}_{\mathrm{A}}$ signifies the share of total GDP of group A relative to world GDP. The last term in Equation (1) given in square brackets is called a size dispersion index and it is an index of countries' similarity. The magnitude of size dispersion index is higher when countries in the group have similar size in terms of their GDP and lower when they are unequal. Debaere (2004) argues that it is an attractive measure especially if one believes the Helpman hypothesis that the increasing fraction of output that developed countries trade among themselves reflects growing intra-industry trade.

Helpman predicts that countries exchange a larger fraction of output as they both become more similar in terms of size and as their total size as a group increases, i.e. as they produce more diverse products. A number of assumptions underlie the derivation of Equation (1). First, it is assumed that there are no trade barriers, so that all countries have identical prices. Second, countries are assumed to specialize in different varieties of a final product. Third, demand is identical and homothetic across countries. The assumption of identical prices across all countries is very restrictive and relaxing this assumption makes the model more realistic. It is common practice to incorporate price indexes to take account of trade barriers countries impose on cross-border trade. The use of countries' general price levels, however, suffers from a number of limitations ${ }^{3}$. There were also other studies that

\footnotetext{
${ }^{1}$ The REM is consistent only if it fulfils the following orthogonality conditions. The use of REM requires $\mu_{\mathrm{ij}} \sim\left(0, \sigma_{\mu}^{2}\right), \mathrm{v}_{\mathrm{ijt}} \sim\left(0, \sigma_{\mathrm{v}}^{2}\right)$, and $\mu_{\mathrm{ij}}$ are independent of $\mathrm{v}_{\mathrm{ijt}}$. Moreover, the explanatory variables have to be independent of the $\mu_{\mathrm{ij}}$ and $v_{\mathrm{ijt}}$ for all cross-sections and time periods. On the other hand, the FEM remains consistent and is not subjected to the above kinds of orthogonality conditions as long as it is free from endogeneity or errors in variables. On the other hand, the REM has the advantage of more efficiency as compared to the FEM. Egger (2002) says that in situations when the REM does not meet the orthogonality requirements, only the FEM is consistent since it wipes out all time invariant effects $\left(\mu_{\mathrm{ij}}\right)$.

${ }^{2}$ The derivation of the equation is found in Helpman and Krugman (1985:165-167) and Feenstra (2004:144-147).

${ }^{3}$ Some of these limitations are given in Feenstra (2004). A myriad of costs (in money, time, and currency risk) involved in making transactions across borders are probably not reflected in aggregate price indexes. Another problem with using price indexes is that they are nearly always measured relative to an arbitrary base period. This makes it impossible to compare the "level" of prices in different places when the base period for each index differs.
} 
suggest the use of exchange rates to capture the effect of price differences (e.g. Bergstrand, 1985, 1989; Oguledo and MacPhee, 1994). The exchange rate was initially considered to play the role of a price index in our model. Nevertheless, since the dependent variable in our model is bilateral trade, the movement of exchange rate affects both trading partners in different ways hence it won't be possible to determine in advance the sign of the exchange rate variable if it appears in our model. For instance, depreciation of the Rand is supposed to increase South Africa's export to its trading partner while it reduces the volume of imports from abroad. In our model, changes in the exchange rate may have no net effect on the volume of bilateral trade. Accordingly, we exclude any indicator of price from our model and expect that the fixed effects term will take care of it should it arises. The FEM specification provides for a mechanism to capture the effects of other variables that do not appear explicitly in the type of equations given as in (1). This study therefore uses a specification that includes a multiplicative fixed effects term to take account of the different prices resulting because of trade barriers and transportation costs.

Hummels and Levinsohn (1995) transfer the sum of GDPs of countries in group A, $Y_{A}$, to the right hand side as appeared in Equation (2) below:

$$
\mathrm{VT}_{\mathrm{A}}=\mathrm{Y}_{\mathrm{A}} \mathrm{S}_{\mathrm{A}}\left[1-\sum_{\mathrm{i} \in \mathrm{A}}\left(\frac{\mathrm{Y}_{\mathrm{i}}}{\mathrm{Y}_{\mathrm{A}}}\right)^{2}\right]
$$

where

$$
\left[1-\sum_{\mathrm{i} \in \mathrm{A}}\left(\frac{\mathrm{Y}_{\mathrm{i}}}{\mathrm{Y}_{\mathrm{A}}}\right)^{2}\right]=1-\left(\mathrm{Y}_{\mathrm{it}} / \mathrm{Y}_{\mathrm{ijt}}\right)^{2}-\left(\mathrm{Y}_{\mathrm{jt}} / \mathrm{Y}_{\mathrm{ijt}}\right)^{2}=\text { Similarity of countries (Sim). }
$$

According to Debaere (2004), the practice of shifting the sum of GDPs to the right side of the equation results in exaggerated R-squares and significant and consistent coefficients that would otherwise be difficult to find especially for trade among non-OECD countries. Furthermore, Hummels and Levinsohn (1995) assumed that the world share of the group represented by A remains constant over the years. Hence, no parameter was estimated for $S_{A}$ and was made part of the fixed effects. This is also indicated to have significant statistical ramifications. Debaere (2004) argues that the coefficient estimated for the product of the sum of GDP of group A and the similarity index takes a positive sign even if there is no relationship between the volume of aggregate trade volume of the group and similarity of countries. This is so due to the correlation between the volume of trade and the aggregate GDP of the group. In order to avoid such limitations, this study builds on the specification of Debaere

$$
\ln \mathrm{VT}_{\mathrm{A}}-\ln \mathrm{Y}_{\mathrm{A}}=\alpha_{\mathrm{A}}+\beta_{1} \ln \mathrm{S}_{\mathrm{At}}+\beta_{2} \ln \operatorname{Sim}_{\mathrm{At}}+\varepsilon_{\mathrm{At}}
$$

Equation (3), which is a logarithmic transformation of Equation (1), is identical with the main equation estimated by Debaere (2004) to show that similarity is more 
important in explaining trade among OECD countries than it does for trade among non-OECD countries. It uses a fixed effects panel estimation technique. Expression (3) contrasts the specifications of Helpman and Hummels and Levinsohn (1995), who assumed that the size of the group relative to the world remains constant over the years. Inclusion of the multiplicative fixed effects term in Equation (1) has been popular in empirical studies and hence the logarithmic transformation suits the balanced panel being considered and is more appropriate for the purpose at hand. Since the use of the logarithmic expression becomes difficult in unbalanced panel data econometrics, the study includes only those trading partner countries for which complete data for the period 1994 to 2004 is available.

Instead of taking bilateral trade volume as a fraction of aggregate GDP as the dependent variable, the second attempt is to transfer the aggregate GDP to the right hand side and merge it with the relative size of the group. This is considered primarily in pursuit of a specification that avoids the endogeneity problem identified by Debaere (2004) in the study of Hummels and Levinsohn (1995). We expect a higher coefficient for the relative size of the group in our estimation by eliminating the group GDP from the denominator in the left hand side of the equation. This makes the size of $\beta_{1}$ in Equation (5) twice as large as the same coefficient in the study of Debaere. This assumes that trade between South Africa and its trading partners with similar economic size may involve a significant portion of intra-industry trade:

$$
\mathrm{VT}_{\mathrm{A}}=2 \mathrm{~S}_{\mathrm{A}}\left[1-\sum_{\mathrm{i} \in \mathrm{A}}\left(\frac{\mathrm{Y}_{\mathrm{i}}}{\mathrm{Y}_{\mathrm{A}}}\right)^{2}\right]
$$

and

$$
\ln \mathrm{VT}_{\mathrm{A}}=\alpha_{\mathrm{A}}+\beta_{1} \ln \mathrm{S}_{\mathrm{At}}+\beta_{2} \ln \operatorname{Sim}_{\mathrm{At}}+\varepsilon_{\mathrm{At}}
$$

In Equations (3) and (4), particularly in the latter, $\beta_{1}$ must not be statistically different from zero if the size of the group relative to the world remains constant over the years. In order to see the significance of this variable in the Helpman theorem, both equations are estimated by excluding this variable and the results are shown in Panel B of Table 1.

The relative size of the group relative to the world and the similarity index are calculated using nominal and real GDPs. Even if calculating these variables using the latter provides a more realistic measure, the estimation is also done using nominal GDP figures to corroborate the findings of the estimation that uses real GDP. The results of these estimations are given separately in the left and right hand side of Table 1. 


\section{Data}

Data covers the period 1994 to 2004 . A balanced panel is employed primarily to make use of the logarithmic transformation of the Helpman's equation. Some of the diagnostic tests also require the use of a balanced panel.

Bilateral trade between South Africa and each of its trading partner countries is determined by summing South Africa's export to and import from each trading partner. The trade data is sourced from Quantec Research and the panel includes a total of 124 countries (excluding South Africa).

The studies of Hummels and Levinsohn (1995) and of Debaere (2004) used aggregate imports and exports. However, since South Africa's mining sector constitute significant part of the country's exports, incorporating this resource intensive sector in the analysis may overshadow the typical nature of the country's bilateral trade from the other sectors of the economy. Hence, instead of aggregate bilateral trade the study focuses solely on the country's manufacturing import and export trade. According to the Standard Industrial Classification (SIC), the study considers all categories between and including SIC 05 and SIC 32.

The share of world GDP of the two trading partners and the similarity index is calculated using the nominal GDP figures collected from UNCTAD. The same source is used to collect countries' population sizes. According to economic theory, the direction of influence between bilateral trade and GDP may be both ways. Most trade theories predict that the size of countries determine the volume of trade. Trade is also believed to be a source of GDP growth. This is likely to introduce endogeneity problem in our estimations. This problem is addressed by using instrumental variables, such as population, to predict GDP figures that will be used in calculating size and similarity indices.

\section{Empirical results and discussion}

The empirical findings from estimating Equations (4) and (5) with nominal GDP figures are given in Columns 1 and 2 of Table 1. Columns 3 and 4 report results from estimating both equations with real GDP figures to construct group size relative to the world and similarity index. Recognizing heterogeneity of South Africa's trading partners and the existence of serial correlation in the panel, all estimations are done on Prais-Winsten ${ }^{4}$ transformed data and panel specific autoregressive order of one is considered in determining the corrected standard errors. It should be remembered that the size of the group relative to the World is assumed to remain constant and its impact is supposed to be captured by the fixed effects term in Panel B.

\footnotetext{
${ }^{4}$ Prais-Winsten transformation is carried out to correct for serial correlation in the data set. It transforms the dependent variable and independent variables to their differences by deducting $\rho$ times the lagged value of each variable from the current value of the same variable. $\rho$ is determined for each crosssections by running ordinary least square on residuals from the original specification on lagged residuals.
} 
Column 5 in Table 1 reports the instrumental variable regression outputs. It is indicated earlier that the volume of trade affects and is affected by the level of income of a country. This means that the direction of influence between bilateral trade and GDP runs both ways. This obviously introduces endogeneity problem in our estimations. The approach of Debaere (2004) is mainly to address this problem. Countries' population is used as an instrumental variable for GDP, so the group share and dispersion index are calculated using predicted GDPs from the first stage regressions.

Table 1: Empirical results

\begin{tabular}{|c|c|c|c|c|c|}
\hline \multirow{3}{*}{$\begin{array}{l}\text { Column } \\
\text { Equation }\end{array}$} & \multicolumn{2}{|c|}{ Nominal } & \multicolumn{2}{|c|}{ Real } & \multirow{3}{*}{$\begin{array}{c}5 \\
\text { (3) with IV }\end{array}$} \\
\hline & 1 & 2 & 3 & 4 & \\
\hline & (3) & (4) & (3) & (4) & \\
\hline \multicolumn{6}{|l|}{ Panel A } \\
\hline Variable & Coefficient & Coefficient & Coefficient & Coefficient & Coefficient \\
\hline Relative & $0,8599^{* * *}$ & $1,9677^{* * *}$ & $1,2113^{* * *}$ & $2,2256^{* * *}$ & $1,2724^{* * *}$ \\
\hline size & $(0,1456)$ & $(0,1483)$ & $(0,056)$ & $(0,0568)$ & $(0,0793)$ \\
\hline \multirow[t]{2}{*}{ Similarity } & $0,6300^{* * *}$ & $0,6253^{* * *}$ & $0,5486^{* * *}$ & $0,5498^{* * *}$ & $0,5291^{* * * *}$ \\
\hline & $(0,0538)$ & $(0,0541)$ & $(0,042)$ & $(0,0424)$ & $(0,0447)$ \\
\hline \multirow{2}{*}{ Constant } & $10,0946^{* * *}$ & $27,9271^{* * * *}$ & $-1,8559^{* * *}$ & $29,2611^{* * *}$ & $12,0289^{* * * *}$ \\
\hline & $(0,6457)$ & $(0,6689)$ & $(0,281)$ & $(0,2914)$ & $(0,3462)$ \\
\hline R-square & 0,60 & 0,95 & 0,92 & 0,96 & 0,62 \\
\hline $\begin{array}{l}\text { Wald } \chi^{2} \\
\text { (2) }\end{array}$ & 352,68 & 680,35 & 755,18 & 1999,28 & 508,82 \\
\hline \multicolumn{6}{|l|}{ Panel B } \\
\hline \multirow[t]{2}{*}{ Similarity } & $0,7155^{* * *}$ & $0,8795^{* * *}$ & $0,7267^{* * *}$ & $0,8890^{* * *}$ & $0,6929^{* * *}$ \\
\hline & $(0,0421)$ & $(0,0417)$ & $(0,0398)$ & $(0,0368)$ & $(0,0400)$ \\
\hline \multirow[t]{2}{*}{ Constant } & $6,0736^{* * *}$ & $18,8798^{* * *}$ & $-7,5579^{* * *}$ & $18,8457^{* * *}$ & $5,9347^{* * *}$ \\
\hline & $(0,1568)$ & $(0,1979)$ & $(0,179)$ & $(0,1963)$ & $(0,1599)$ \\
\hline R-square & 0,58 & 0,96 & 0,91 & 0,95 & 0,53 \\
\hline $\begin{array}{l}\text { Wald } \chi^{2} \\
\text { (1) }\end{array}$ & 288,6 & 444,05 & 332,40 & 583,22 & 299,00 \\
\hline
\end{tabular}

NB: Panel corrected standard errors (using Praise-Winsten transformation) are given in parentheses.

$*,(* *)$ and $(* * *)$ indicate significance at 90,95 and $99 \%$ confidence intervals, respectively.

* Population size is used as instrumental variable (IV) to construct variables representing relative size of the group and similarity of South Africa and each of its trading partners.

According to the Helpman theorem, both coefficients for the group's share and similarity indexes are expected to take on a value of 1 . Throughout all estimations, though the coefficient of similarity index is not equal to one, the sign of the coefficient is positive as predicted. Despite the varying magnitudes of the coefficients particularly of the group's share of the world GDP, both variables have economically consistent signs throughout all estimations.

It is established in the study of Debaere (2004) that similarity of trading partners plays an important role in explaining trading relationships that exists between developed economies like the OECD member states. He further indicated that the trading relationships among non-OECD countries could not be explained by the 
similarity index. As indicated earlier, the Helpman theorem and any gravity equation specification is not supposed to explain trade among developing countries. It is recalled from the previous sections that Debaere (2004) found that the Helpman theorem does not hold among non-OECD countries.

However, our findings appear to contrast those of Debaere (2004). Considering the developing country status of South Africa, the country's bilateral trade should not have responded positively to the similarity index. In this paper, similarity is found to reasonably explain the bilateral trade of South Africa and its trading partners. This proves that the majority of manufacturing trade between South Africa and those countries with similar economic size involves considerable amount of intraindustry trade. This also suggests that manufacturing firms in South Africa are able to differentiate their products in order to be competitive in the world market. Despite the claim that most South African products are resource-based, these products are different from the ones produced by a similar country because of product differentiation. It is important to note that the Helpman theorem is one of imperfect competition models. It may therefore be the case that the pattern of manufacturing trade between South Africa and those similar countries can be explained by some of the imperfect competition models. Moreover, in spite of the official labelling of South Africa as a developing country, it can be argued that its manufacturing sector exhibits characteristics of a typical developed economy.

\section{Testing the econometric findings with a sample of actual trade data}

The econometric results given above demonstrate that intra-industry trade is greater between South Africa and those countries having comparable economic size than with those having bigger and smaller economic size than South Africa. We considered a sample of countries in this section to see whether the econometric findings are born in practice. The sample consists of a group of 12 countries that are economically similar and another group of 12 that are dissimilar with South Africa. The selection is done using the size dispersion index given in section four above. Those similar countries that form part of the sample are Thailand, Venezuela, Greece, Poland, Norway, Denmark, Finland, Hong Kong, Israel, Portugal, Indonesia, and Turkey. These countries measure between 0,48 and 0,50 using the size dispersion index. As we remember, the size dispersion index gets closer to 0,5 as the countries in the group become more similar in terms of GDP. We select equal number of larger and smaller countries in forming the second group. The larger countries included in this sub-sample are United States, Japan, Germany, United Kingdom, France and Italy. The smaller countries considered in the second sample are predominantly African countries, namely Liberia, Comoros, Guinea Bissau, Equatorial Guinea, Gambia and Seychelles. Using the same size dispersion index, South Africa and each country in the second group (composed of larger and smaller countries) measure between 0,0022 and 0,1858 . 
The marginal intra-industry trade measure, specifically the Brülhart $\mathrm{B}^{5}$ measure, was calculated using import and export figures of South Africa between 1994 and 2004 for the 28 two-digit SIC $^{6}$ industrial classifications of the manufacturing sector. The average Brülhart B measure for the two groups of countries is calculated and compared for each of the 28 industrial classifications. The result indicates that intra-industry trade is greater with the group of similar countries in the majority of the cases (15 out of the 28 industrial classifications). In the remaining cases, the role of inter-industry trade is marginally or significantly higher than intra-industry trade.

\section{Conclusion}

Developing countries, like South Africa, are expected to have lower levels of intraindustry trade because of the resource-based nature of products that they typically produce. Based on the study of Isemonger (2000) that employs the Grubel-Llyod index on data between 1993 and 1996, the overall level of intra-industry trade of the South African economy is found to be low as mentioned earlier. The overall low level may partly be due to incorporating the entire sectors producing primary and manufactured products in the analysis.

This study, however using a regression analysis, determined that the bilateral manufacturing trade of South Africa between 1994 and 2004 responds significantly and positively to the similarity and the world share of South Africa and its trading partners. This demonstrates that intra-industry trade plays an important role in the South African economy. The fact that South Africa's bilateral trade responds positively to the size dispersion index may suggest that South Africa's manufacturing sector appears to share the characteristics of those of developed economies.

A number of policy implications can be drawn from this study. South Africa's foreign trade rose dramatically over the past decade and expected to do so as the result of the increasingly globalizing world and the various trade arrangements that the country entered into and is negotiating. Given its numerous trade arrangements, the finding of booming intra-industry trade implies the smooth adjustment of its economy to the needs of increasing foreign trade. Theoretically, the cost of adjustment is lower with intra-industry trade than with inter-industry trade. Since intra-industry trade is usually associated with trade among developed economies, higher intra-industry trade in South Africa can be a crude indicator of the level of development of the South African economy.

\footnotetext{
${ }^{5}$ The Brülhart B measure calculated using the following formula:

$\mathrm{B}^{\mathrm{A}}=1-\frac{\left|\Delta \mathrm{X}_{\mathrm{SA}, \mathrm{i}}-\Delta \mathrm{M}_{\mathrm{i}, \mathrm{SA}}\right|}{\left|\Delta \mathrm{X}_{\mathrm{SA}, \mathrm{i}}\right|+\left|\Delta \mathrm{M}_{\mathrm{i}, \mathrm{SA}}\right|}$

${ }^{6}$ If easily available, four-digit SIC (standard industrial classification) could have given us better estimates as this level of disaggregation appear to correspond closest to the concept of an industry.
} 
Higher intra-industry trade also suggests similarity of resource endowments among trading partners. However, this does not pre-empt all other factors that might boost bilateral trade but different from the similarity of resource endowments argued to support classical trade theories. Even if the products that are exported by South Africa are resource based carrying relatively low potential for differentiation, similarity in size could still increase the level of exports and imports. We believe that countries of similar size would impose lower reciprocal trade barriers as countries of similar size do not see each other as powerful enough to reap the entire benefit from the bigger joint market.

\section{References}

Bergstrand, J H (1985): “The Gravity Equation in International Trade: Some Microeconomic Foundations and Empirical Evidence", The Review of Economics and Statistics, 67(3), 474-481.

Bergstrand, J H (1989): "The Generalized Gravity Equation, Monopolistic Competition, and the Factor-proportions Theory in International Trade", The Review of Economics and Statistics, 71(1), 143153.

Debaere, P (2004): "Monopolistic Competition and Trade, Revisited: Testing the Model Without Testing for Gravity", Journal of International Economics, 66, 249-266.

Egger, P (2002): “An Econometric View on the Estimation of Gravity Models and the Calculation of Trade Potentials", The World Economy, 25(2), 297-312.

Feenstra, R C (2004): Advanced International Trade: Theory and Evidence. Princeton University Press, Princeton.

Helpman, E (1987): "Imperfect Competition and International Trade: Evidence from Fourteen Industrial Countries", Journal of the Japanese and International Economies, 1, 62-81.

Hummels, D and Levinsohn, J (1995): "Monopolistic Competition and International Trade: Reconsidering the Evidence", Quarterly Journal of Economics, 110(3), $799-836$.

Isemonger, A G (2000): "The Estimation of Intra-industry Trade in South Africa", Development Southern Africa, 17(1), 53-63.

Oguledo, V I and MacPhee, C R (1994): "Gravity Models: a Reformulation and an Application to Discriminatory Trade Arrangement", Applied Economics, 26, 107-120.

Parr, R G (2000): “Specialization in South African Manufactures Trade, 1993-1998”, South African Journal of Economics, 68, 298-306. 
